\title{
The oribatid mite subgenus Galumna (Galumna) (Acari, Oribatida, Galumnidae) in the Philippines
}

\author{
Sergey G. Ermilov', Leonila Corpuz-Raros², Andrei V. Tolstikov' \\ I Tyumen State University, Tyumen, Russia 2 Crop Protection Cluster, College of Agriculture and Museum of \\ Natural History, University of the Philippines Los Baños, Los Baños, Philippines \\ Corresponding author: Sergey G. Ermilov (ermilovacari@yandex.ru)
}

Academic editor: V. Pesic | Received 14 September 2014 | Accepted 13 October 2014 | Published 4 November 2014

http://zoobank.org/9FEDDB41-5661-4EF8-BFAD-25247359CBBB

Citation: Ermilov SG, Corpuz-Raros L, Tolstikov AV (2014) The oribatid mite subgenus Galumna (Galumna) (Acari, Oribatida, Galumnidae) in the Philippines. ZooKeys 452: 1-13. doi: 10.3897/zookeys.452.8212

\begin{abstract}
Five species of the subgenus Galumna (Galumna) (Acari, Oribatida, Galumnidae) are registered in the Philippine oribatid mite fauna. A new species, $G$. (G.) makilingensis sp. n., is described; it is most similar morphologically to $G$. (G.) tokyoensis Aoki, 1966, but differs from the latter by the morphology of porose areas $A a$ and $A p$, rostral setae, and length of interlamellar setae. Three species, $G$. (G.) crenata Deb \& Raychaudhuri, 1975, G. (G.) cf. exigua Sellnick, 1925 and $G$. (G.) khoii Mahunka, 1989, are recorded in the Philippines for the first time. The species $G$. (G.) crenata is redescribed. An identification key to the Philippine species of Galumna (Galumna) is given.
\end{abstract}

\section{Keywords}

Oribatida, Galumnidae, Galumna (Galumna), new species, supplementary description, key, Philippines

\section{Introduction}

Galumna (Galumna) is the largest subgenus of Galumna Heyden, 1826, comprising 161 species, which have a cosmopolitan distribution (based on data by Subías 2004, updated 2014). In the course of taxonomic identification of oribatid mites from the Philippines, we found five species of this subgenus: one species is represented as a new to science and other four are already known ones (see Checklist section below). At present, only G. (G.) flabellifera Hammer, 1958 was reported from the Philippines (see Corpuz-Raros 1979; Corpuz-Raros and Gruèzo 2011).

Copyright Sergey G. Ermilov et al. This is an open access article distributed under the terms of the Creative Commons Attribution License (CC BY 4.0), which permits unrestricted use, distribution, and reproduction in any medium, provided the original author and source are credited. 
The primary goal of the present paper is to describe and illustrate a new species. The secondary goal is to make a supplementary description of $G$. $(G$.) crenata based on the Philippine material, which was originally described by Deb and Raychaudhuri (1975) from India. The first description of $G$. (G.) crenata was incomplete, and lacks information on the length of morphological structures, leg setation, solenidia, gnathosoma, and the illustrations were insufficient.

In addition, we present an identification key to the Philippine species of Galumna (Galumna) below.

\section{Material and methods}

The species of Galumna (Galumna) were found in 11 sites:

L-1 Philippines, Mindanao Island, Nasipit Lumber Company, Tungao, Agusan del Norte, in leaf litter, 28.V.1977, collected by J.M. Sotto and R.C. Garcia.

L-3 Philippines, Luzon Island, Animal Science pasture, University of the Philippines Los Bańos campus, College, Laguna, in litter from pasture, 28.VI.1975, collected by J.M. Sotto and R.C. Garcia.

L-5 Philippines, Luzon Island, Mt. Makiling, Makiling Botanic Gardens, Los Baños, Laguna, in topsoil from plantation of Moluccan Sau (Albizia falcataria), 8.VI.1975, collected by J.M. Sotto and R.C. Garcia.

L-16 Philippines, Luzon Island, Mt. Makiling, Makiling Botanic Gardens, Los Baños, Laguna, in litter from undistrurbed secondary forest, 1.VI.1975, collected by J.M. Sotto and R.C. Garcia.

L-20 Philippines, Luzon Island, Mt. Makiling, Makiling Botanic Gardens, Los Baños, Laguna, in litter from plantation of molave (Vitex parviflora), 19.VII.1975, collected by J.M. Sotto and R.C. Garcia.

L-21 Philippines, Luzon Island, Maddela, Quirino, in bamboo leaf litter, 11.XI.1975, collected by P.S. Raros.

L-23 Philippines, Panay Island, Panay State Polytechnic College campus, Mambusao, Capiz, in grass litter, 12.X.1990, collected by A.M. Almeroda.

L-34 Philippines, Luzon Island, Tagga, Tuguegarao, Cagayan, in forest litter, 14.XI.1975, collected by P.S. Raros.

L-40 Philippines, Luzon Island, Animal Science pasture, University of the Philippines Los Baños campus, College, Laguna, in litter at base cogon (Imperata cylindrica), 16.IX.1975, collected by J.M. Sotto and R.C. Garcia.

L-43 Philippines, Mindanao Island, Nasipit Lumber Company, Tagpange, Tungao, Agusan del Norte, in litter from Albizia falcataria-Ipomoea sp., fern vegetation, 28.IV.1975, collected by R.S. Raros.

L-45 Philippines, Luzon Island, Mt. Makiling, on north trail to peak, Los Baños in litter under pakong-lawit (Goniophlebium percusum, Polypodiaceae, fern), 4.V.1975, collected by J.M. Sotto. 
Specimens were mounted in lactic acid on temporary cavity slides for measurement and illustration. The body length was measured in lateral view, from the tip of the rostrum to the posterior edge of the ventral plate. The notogastral width refers to the maximum width in dorsal aspect. Lengths of body setae were measured in lateral aspect. All body measurements are presented in micrometers. Formulae for leg setation are given in parentheses according to the sequence trochanter-femur-genu-tibia-tarsus (famulus included). Formulae for leg solenidia are given in square brackets according to the sequence genu-tibia-tarsus. General terminology used in this paper follows that of Grandjean (summarized by Norton and Behan-Pelletier 2009). Drawings were made with the drawing tube using the Carl Zeiss transmission light microscope "Axioskop-2 Plus" at Tyumen State University, Russia.

\section{Checklist of registered Galumna (Galumna) species}

Galumna (Galumna) crenata Deb \& Raychaudhuri, 1975. Distribution: India. Locality: L-1. First record in the Philippines.

Galumna (Galumna) cf. exigua Sellnick, 1925. Distribution: Sumatra. Localities: L-1, L-20, L-21, L-23, L-43, L-45. First record in the Philippines.

Galumna (Galumna) flabellifera Hammer, 1958. Distribution: Pantropics and Subtropics. Localities: L-1, L-3, L-5, L-21, L-23, L-34.

Galumna (Galumna) khoii Mahunka, 1989'1. Distribution: Vietnam. Localities: L-3, L-16, L-23, L-40. First record in the Philippines.

Galumna (Galumna) makilingensis sp. n.: Locality: L-45

\section{Results}

Description of Galumna (Galumna) makilingensis sp. n. http://zoobank.org/4BC74FB7-37C4-4670-8C6D-0BB8BA67C262 Figs $1-4$

Diagnosis. With generic characters of Galumna as summarized by Ermilov et al. (2013). Body size: 647-680 × 498-547. Rostrum pointed. Rostral setae of medium size, ciliate. Lamellar and interlamellar setae long, slightly barbed. Bothridial setae spindle-form. Lamellar lines very strong, divergent in distal parts to sublamellar lines. Anterior notogastral margin developed. Four pairs of porose areas present; $A a$ boomerang-like, other rounded or oval. Median pore present. Postanal porose area long, elongated.

Description. Measurements. Body length: 647 (holotype, female), 680 (one paratype, female); notogaster width: 498 (holotype), 547 (one paratype).

It is possible that Galumna (Galumna) khoii Mahunka, 1989 is a junior synonym of $G$. (G.) lanceata (Oudemans, 1900) (see Ermilov and Anichkin 2014). 


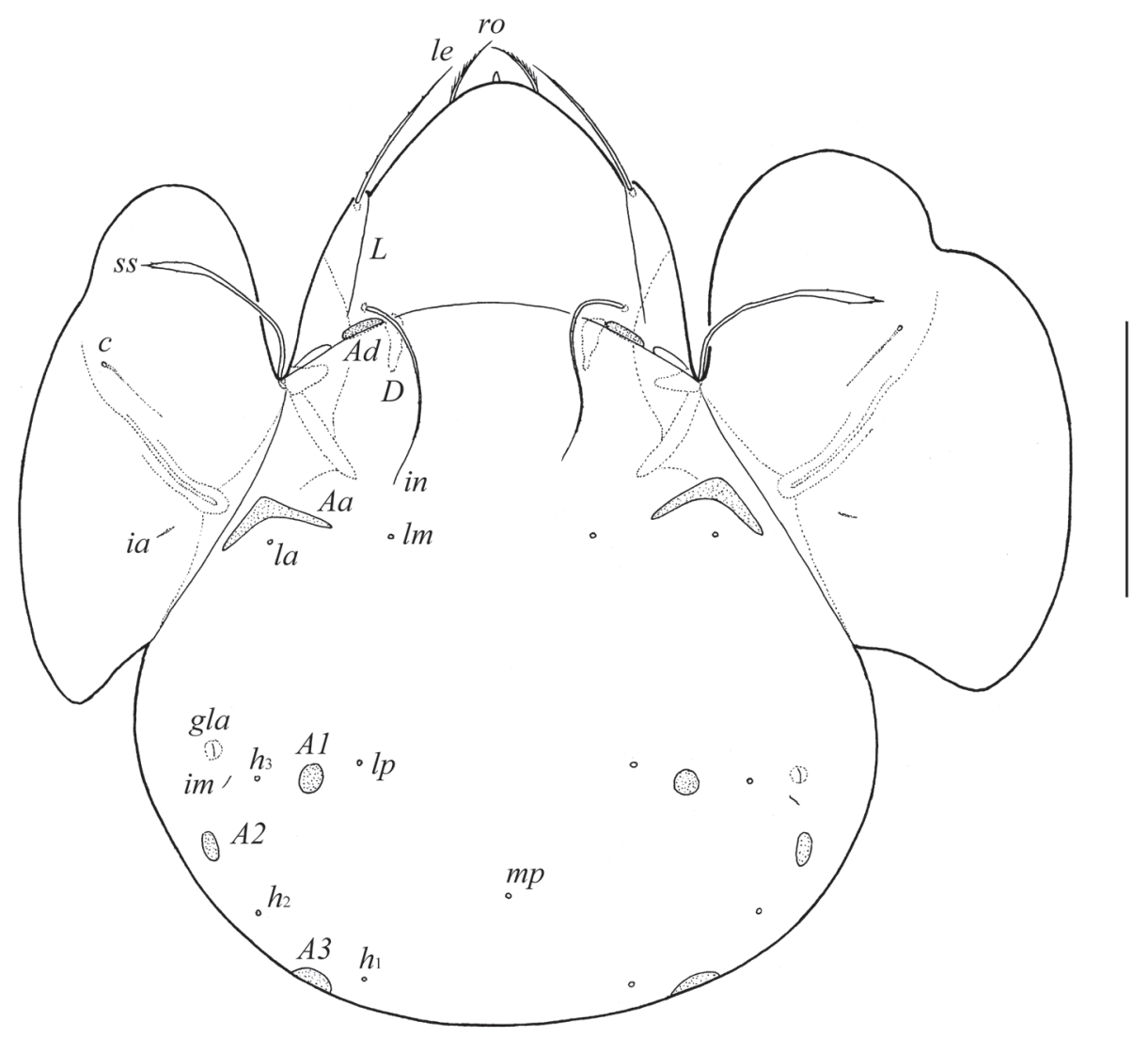

Figure I. Galumna (Galumna) makilingensis sp. n., adult: dorsal view. Scale bar $200 \mu \mathrm{m}$.

Integument. Body color brown. Body surface smooth.

Prodorsum. Rostrum pointed. Rostral setae (ro, 49-57) setiform, ciliate unilaterally. Lamellar (le, 118-127) and interlamellar (in, 172-184) setae setiform, slightly barbed. Bothridial setae (ss, 135-147) spindle-form, with long stalk and short, slightly barbed head. Exobothridial setae and their alveoli absent. Porose areas $\mathrm{Ad}$ oval, transversally oriented $(24-32 \times 6-10)$. Sublamellar lines $(S)$ distinct, thin, curving backwards. Lamellar lines $(L)$ very strong, parallel in basal parts and divergent in distal parts to sublamellar lines.

Notogaster. Anterior notogastral margin developed. Dorsophragmata $(D)$ of medium size, longitudinally elongated. Notogastral setae represented by 10 pairs of alveoli. Four pairs of porose areas with distinct borders: $A a$ boomerang-like (90-102 × $8-16)$, other porose areas rounded or oval; $A 1(20-24 \times 12-16$ or diameter 16-20), A2 (24-32 × 12-16 or diameter 16-20) and A3 (24-45 × 20-24). Alveoli la inserted posteriorly to $A a$. Lyrifissures im and opisthonotal gland openings ( $g$ la located laterally to $A 1$. Median pore $(m p)$ present, located little posterior to virtual line connecting porose areas $A 2$. 


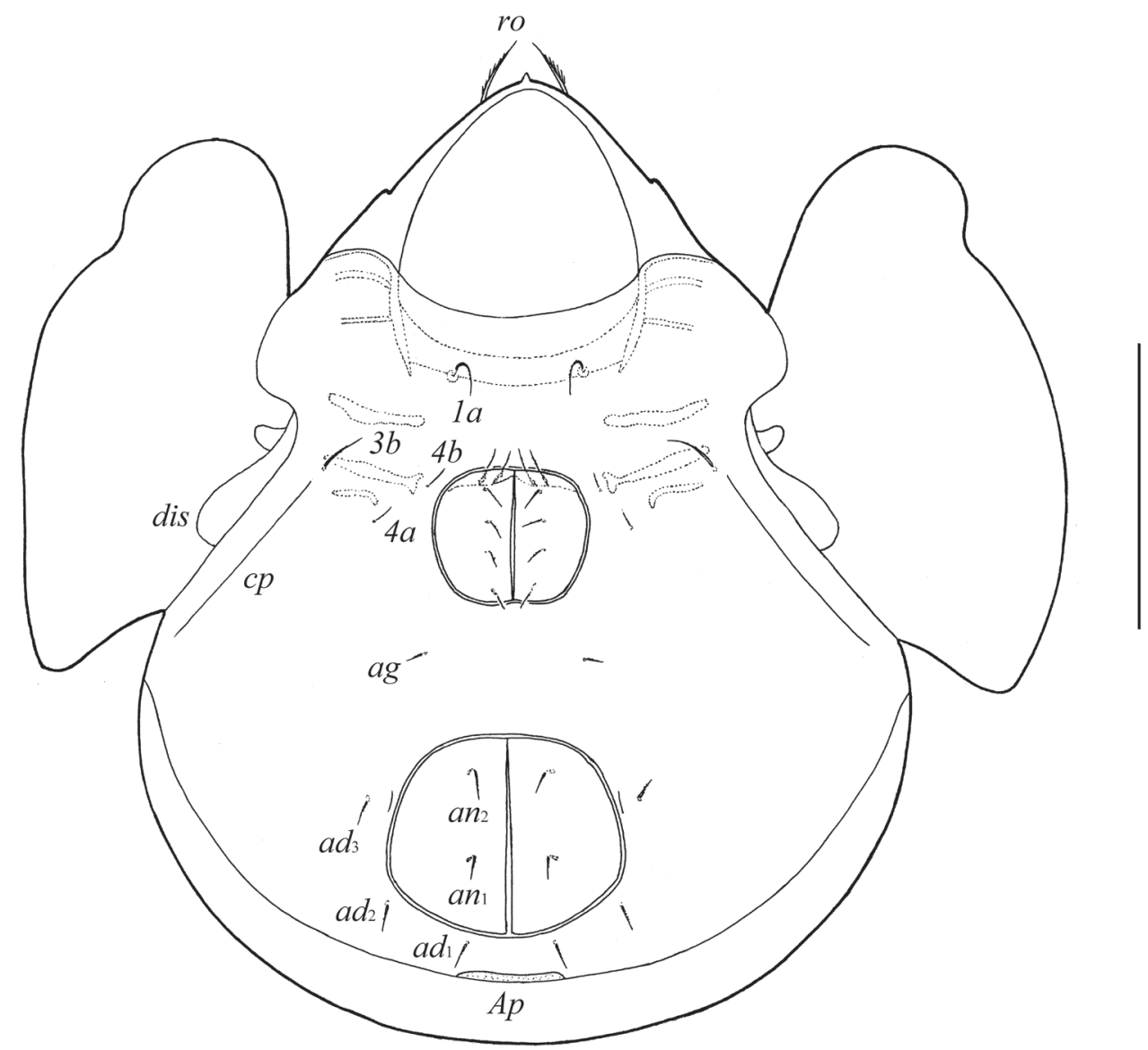

Figure 2. Galumna (Galumna) makilingensis sp. n., adult: ventral view (gnathosoma and legs not illustrated). Scale bar $200 \mu \mathrm{m}$.

Gnathosoma. Morphology of subcapitulum, palps and chelicerae generally typical for species of the subgenus Galumna (Galumna) (for example, Engelbrecht 1969; Ermilov and Anichkin 2011; Ermilov et al. 2011). Subcapitulum longer than wide $(184 \times 155)$. Subcapitular setae simple, slightly barbed: $a(32-36)$ longer than $m$ and $h$ (both 24-28). Two pairs of adoral setae (20) setiform, barbed. Palps (135-139) with setation $0-2-1-3-9(+\omega)$. Solenidion straight, thickened, blunt-ended, attached to eupathidium. Chelicerae (229) with two setiform, barbed setae; cha (57) longer than chb (32). Trägårdh's organ distinct, tapered.

Epimeral and lateral podosomal regions. Apodemes (1, 2, sejugal, 3) well visible. Four pairs of setiform, slightly barbed epimeral setae present; $1 a$ and $3 b(41-49)$ longer than $4 a$ and $4 b$ (24-32). Pedotecta II rectangular, rounded anteriorly in ventral view. Discidia (dis) rounded distally. Circumpedal carinae $(c p)$ of medium length, directed to $3 b$. 

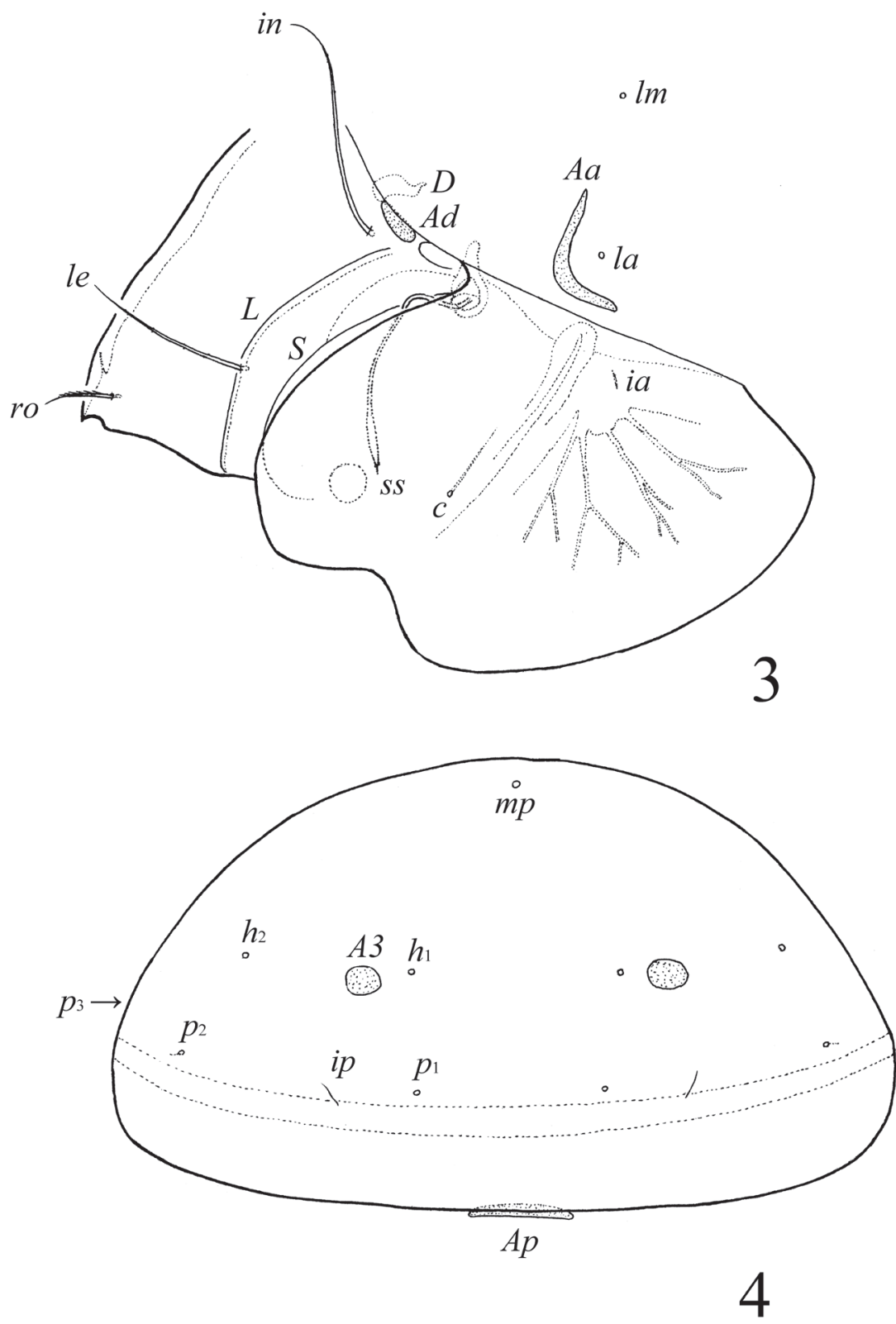

Figures 3-4. Galumna (Galumna) makilingensis sp. n., adult: 3 dorso-lateral view of prodorsum, left pteromorph and anterior part of notogaster (gnathosoma and leg I not illustrated) $\mathbf{4}$ posterior view of notogaster. Scale bar $200 \mu \mathrm{m}$.

Anogenital region. Six pairs of genital $\left(g_{1}-g_{6}, 20-24\right)$, one pair of aggenital (ag, 20-24), two pairs of anal $\left(a n_{1}, a n_{2}, 28-32\right)$ and three pairs of adanal $\left(a d_{1}-a d_{3}, 28-32\right)$ setae setiform, slightly barbed. Anal and adanal setae slightly thicker than genital and 
Table I. Leg setation and solenidia of Galumna (Galumna) makilingensis sp. n. (same data for $G$. (G.) crenata Deb \& Raychaudhuri, 1975).

\begin{tabular}{l|l|l|l|l|l}
\hline Leg & Trochanter & Femur & Genu & Tibia & Tarsus \\
\hline I & $v^{\prime}$ & $d,(l), b v^{\prime \prime}$ & $(l), v^{\prime} \sigma$ & $(l),(v), \varphi_{1}, \varphi_{2}$ & $(f t),(t c),(i t),(p),(u),(a), s,(p v), v^{\prime},(p l), l^{\prime \prime}, \varepsilon, \omega_{1}, \omega_{2}$ \\
\hline II & $v^{\prime}$ & $d,(l), b v^{\prime}$ & $(l), v^{\prime}, \sigma$ & $(l),(v), \varphi$ & $(f t),(t c),(i t),(p),(u),(a), s,(p v), \omega_{1}, \omega_{2}$ \\
\hline III & $v^{\prime}$ & $d, e v^{\prime}$ & $l^{\prime}, \sigma$ & $l^{\prime},(v), \varphi$ & $(f t),(t c),(i t),(p),(u),(a), s,(p v)$ \\
\hline IV & $v^{\prime}$ & $d, e v^{\prime}$ & $d, l^{\prime}$ & $l^{\prime},(v), \varphi$ & $f t^{\prime \prime},(t c),(p),(u),(a), s,(p v)$ \\
\hline
\end{tabular}

Roman letters refer to normal setae ( $\varepsilon$ to famulus), Greek letters to solenidia. Single prime ( $)$ marks setae on anterior and double prime (") setae on posterior side of the given leg segment. Parentheses refer to a pair of setae.

aggenital setae. Anterior edge of genital plates with two setae. Adanal setae $a_{3}$ inserted laterally to adanal lyrifissures $i a d$. Postanal porose area $(A p)$ long, elongated, transversally oriented $(61-77 \times 8-12)$.

Legs. Morphology of leg segments, setae and solenidia generally typical for species of the subgenus Galumna (Galumna) (for example, Engelbrecht 1969; Ermilov and Anichkin 2011; Ermilov et al. 2011; Bayartogtokh and Akrami 2014). Formulae of leg setation and solenidia: I (1-4-3-4-20) [1-2-2], II (1-4-3-4-15) [1-1-2], III (1-2-1-3-15) [1-1-0], IV (1-2-2-3-12) [0-1-0]; homology of setae and solenidia indicated in Table 1.

Material examined. Holotype (female) and one paratype (female): L-45.

Type deposition. The holotype is deposited in the collection of the Zoological Institute of the Russian Academy of Sciences, St. Petersburg, Russia; one paratype (dissected) is deposited in the collection of the Tyumen State University Museum of Zoology, Tyumen, Russia.

Etymology. The specific name "makilingensis" refers to the type locality, Mt. Makiling, the forest reservation of the University of the Philippines Los Baños.

Comparison. In having large body size, pointed rostrum, spindle-form bothridial setae, long prodorsal setae, anterior notogastral margin, four pairs of notogastral porose areas, Galumna (Galumna) makilingensis sp. n. is most similar to Galumna (Galumna) tokyoensis Aoki, 1966 from the Palaearctic region (Aoki 1966). However, it clearly differs from the latter by the boomerang-like porose areas $A a$ and long, elongated postanal porose area (versus both oval in $G$. (G.) tokyoensis), ciliate rostral setae (versus smooth in $G$. $(G$.) tokyoensis) and interlamellar setae longer than lamellar setae (versus similar in length in $G$. (G.) tokyoensis).

Also, in having large body size, bothridial setae with dilated head, long prodorsal setae, anterior notogastral margin, four pairs of notogastral porose areas, $A a$ boomerang-like, Galumna (Galumna) makilingensis sp. n. is most similar to Galumna (Galumna) cuneata Aoki, 1961 from the Palaearctic region (Aoki 1961). However, it clearly differs from the latter by the pointed rostrum (versus rounded in $G$. $(G$.) cuneata), ciliate rostral setae (versus smooth in $G$. $(G$. $)$ cuneata), interlamellar setae longer than lamellar setae (versus similar in length in $G$. (G.) cuneata) and spindle-form bothridial setae (versus clavate in $G$. $(G$.) cuneata). 


\section{Supplementary description of Galumna (Galumna) crenata Deb \& Raychaudhuri, 1975}

Figs 5-8

Description. Measurements. Body length: 348-390 (four specimens, two females and two males); notogaster width: 258-290 (four specimens).

Integument. Body color brown. Body surface smooth, but ventral side covered by the microgranular cerotegument (diameter of granules less than 1), visible only under high magnification $(\times 1000)$ in dissected specimens. Genital plates with one longitudinal stria in medial parts.

Prodorsum. Rostrum rounded. Rostral setae (24-32) setiform, smooth. Lamellar and interlamellar setae minute (both 6-8), thin, smooth. Bothridial setae (49-57) clavate, with long stalk and shorter, rounded and weakly barbed distally head. Exobothridial

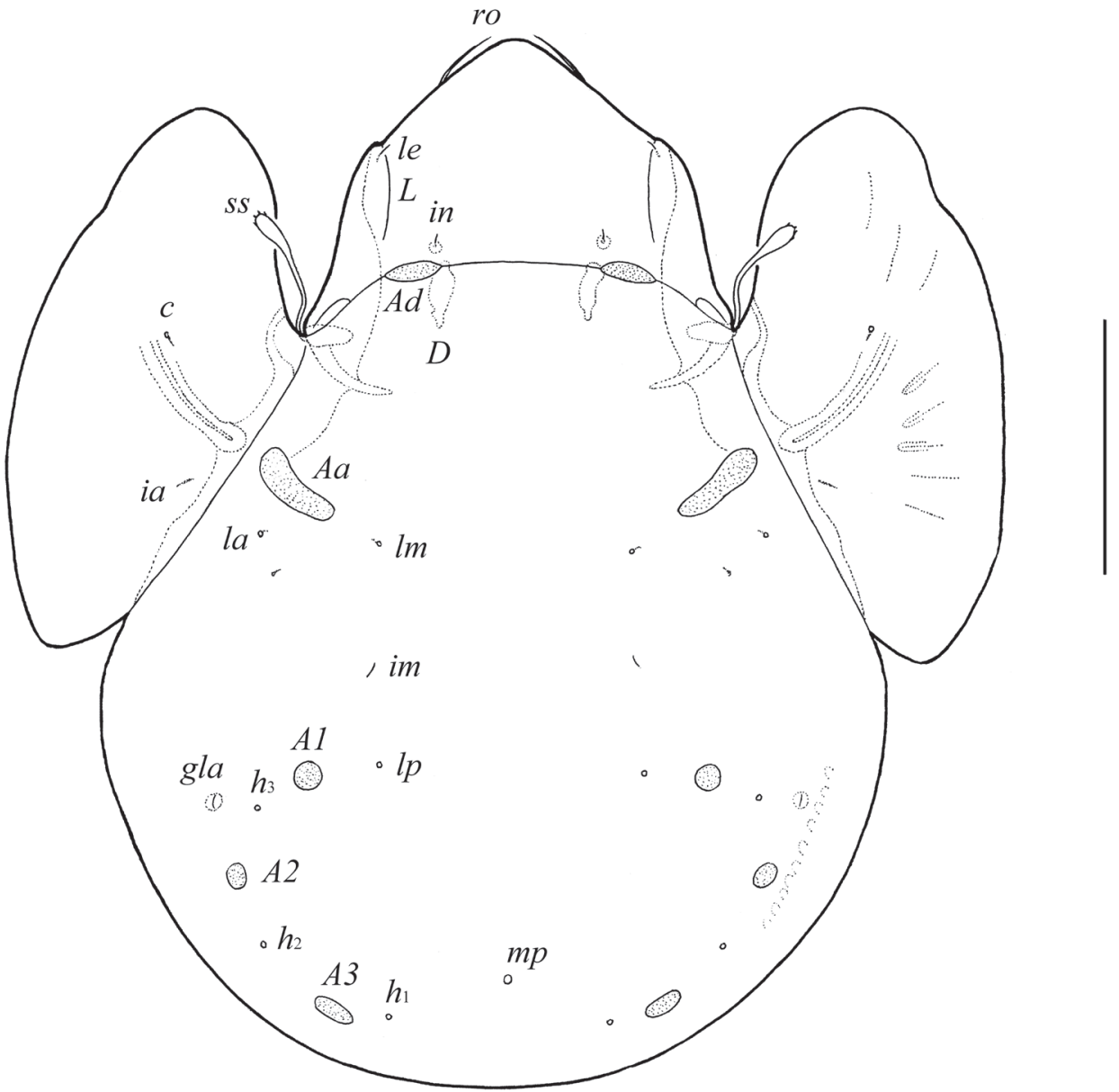

Figure 5. Galumna (Galumna) crenata Deb \& Raychaudhuri, 1975, adult: dorsal view. Scale bar $100 \mu \mathrm{m}$. 


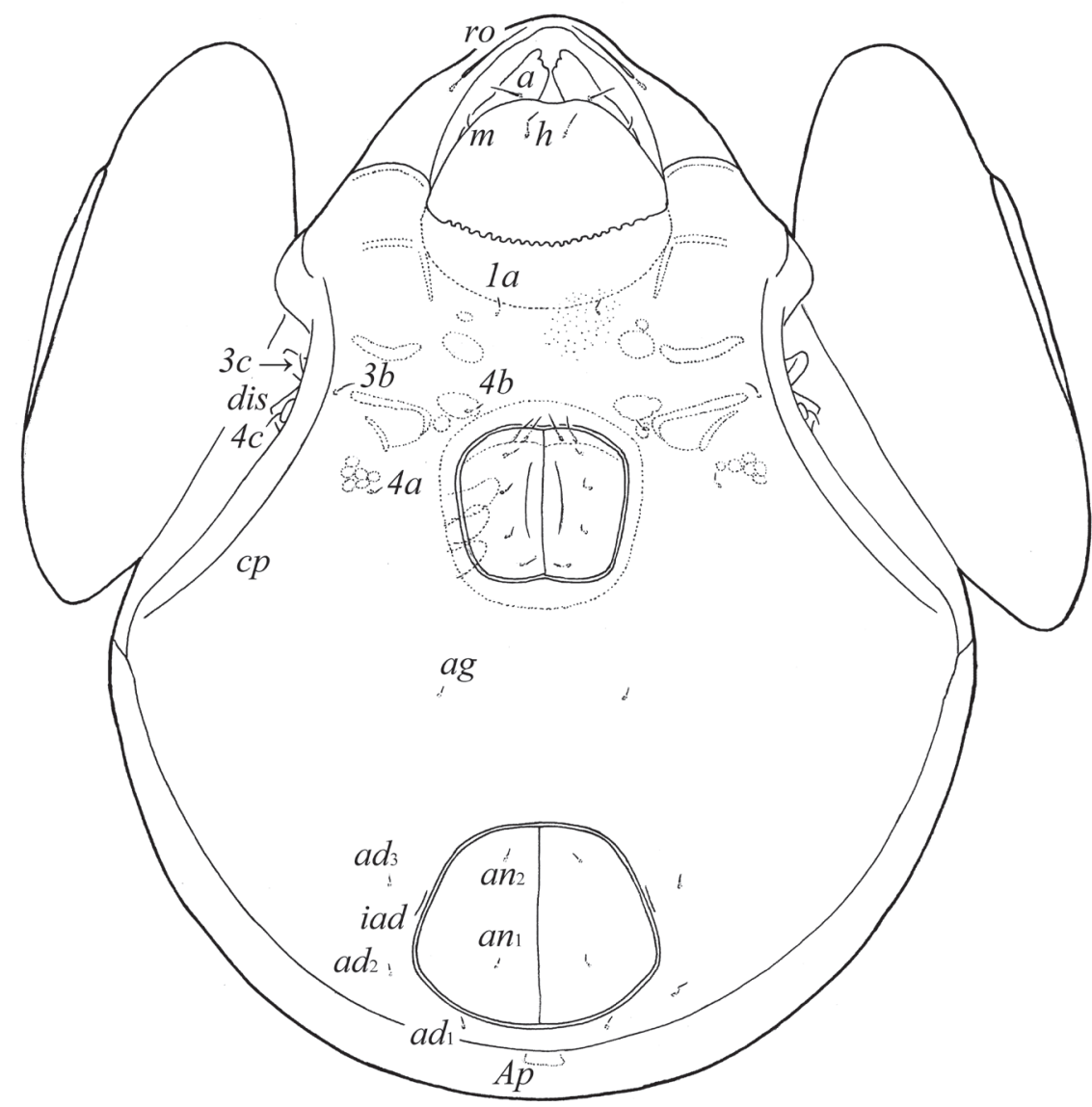

Figure 6. Galumna (Galumna) crenata Deb \& Raychaudhuri, 1975, adult: ventral view (legs not illustrated). Scale bar $100 \mu \mathrm{m}$.

setae and their alveoli absent. Porose areas $A d$ large, oval, transversally oriented (20-22 $\times 6-8$ ). Lamellar and sublamellar lines distinct, thin, parallel, curving backwards.

Notogaster. Anterior notogastral margin developed, but sometimes poorly visible. Dorsophragmata of medium size, longitudinally elongated. Notogastral setae represented by 10 pairs of alveoli. Four pairs of porose areas with distinct borders: $A a$ large, boot-shaped or weakly triangular, transversally oriented (32-36 × 12-16); A1, $A 2$ (diameter of both 8-16) and $A 3$ (diameter of 14-20) rounded. Alveoli la inserted posteriorly to $A a$. Lyrifissures im located between $l m$ and $l p$. Opisthonotal gland openings located laterally to $A 1$. Median pore present, located little anterior to virtual line connecting porose areas $A 3$.

Gnathosoma. Morphology of subcapitulum, palps and chelicerae generally typical for species of the subgenus Galumna (Galumna) (for example, Engelbrecht 1969; Ermilov and Anichkin 2011; Ermilov et al. 2011). Subcapitulum longer than wide (90-94 × 82-68). Subcapitular setae simple, smooth: $a(14-16)$ longer and thicker 


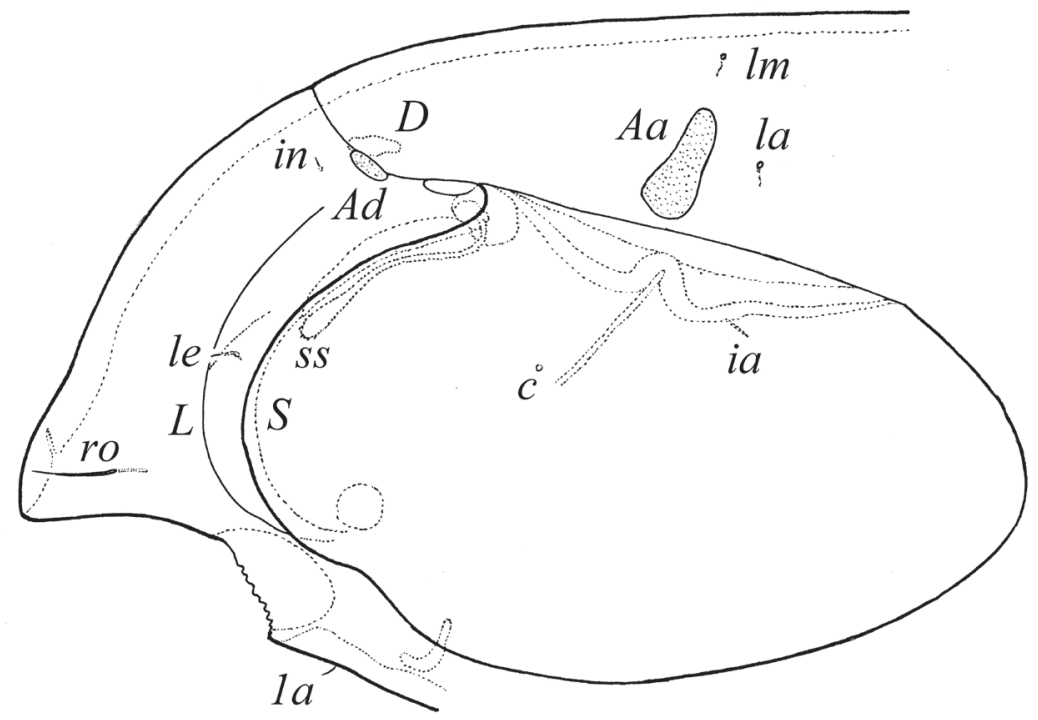

7

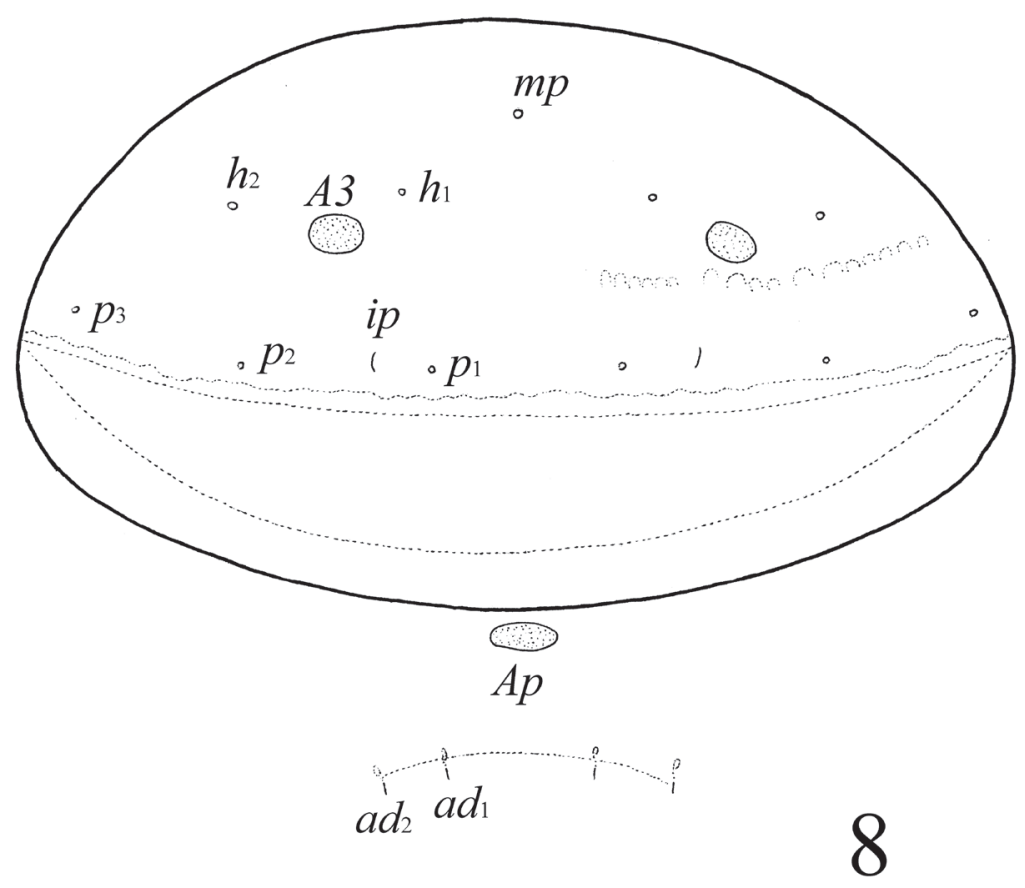

Figures 7-8. Galumna (Galumna) crenata Deb \& Raychaudhuri, 1975, adult: 7 lateral view of prodorsum, left pteromorph and anterior part of notogaster (gnathosoma and leg I not illustrated) 8 posterior view of notogaster and adanal setae $a d_{1}$ and $a d_{2}$. Scale bar $100 \mu \mathrm{m}$. 
than $m$ and $h$ (both 6-8). Two pairs of adoral setae (8) setiform, slightly barbed. Palps (57) with setation $0-2-1-3-9(+\omega)$. Solenidion straight, thickened, blunt-ended, attached to eupathidium. Chelicerae (106-110) with two setiform, barbed setae; cha (36) longer than chb (20). Trägårdh's organ distinct, tapered.

Epimeral and lateral podosomal regions. Anterior tectum of epimere I with numerous rectangular teeth. Apodemes (1,2, sejugal, 3$)$ well visible. Six pairs of thin, smooth epimeral setae (8-12) present. Setae $4 c$ inserted on tubercle. Pedotecta II rectangular, rounded anteriorly in ventral view. Discidia triangular. Circumpedal carinae long, directed to pedotecta I.

Anogenital region. Six pairs of genital setae $\left(g_{1}, g_{2}, 8, g_{3}-g_{6}, 4-6\right)$, one pair of aggenital $(a g, 6-8)$, two pairs of anal $\left(a n_{1}, a n_{2}, 8\right)$ and three pairs of adanal $\left(a d_{1}-a d_{3}, 8\right)$ setae thin, smooth. Anterior edge of genital plates with two setae. Adanal setae $a d_{3}$ inserted laterally to adanal lyrifissures iad. Postanal porose area oval, transversally oriented (12-20 × 6-8).

Legs. Morphology of leg segments, setae and solenidia generally typical for species of the subgenus Galumna (Galumna) (for example, Engelbrecht 1969; Ermilov and Anichkin 2011; Ermilov et al. 2011; Bayartogtokh and Akrami 2014). Formulae of leg setation and solenidia: I (1-4-3-4-20) [1-2-2], II (1-4-3-4-15) [1-1-2], III (1-2-1-3-15) [1-1-0], IV (1-2-2-3-12) [0-1-0]; homology of setae and solenidia indicated in Table 1.

Material examined. Four specimens (two females and two males): L-1.

Remarks. Galumna (Galumna) crenata distinctly differs from other species of the sugenus by the presence of dentate anterior tectum of epimere I. The available Philippine specimens of this species are morphologically and in general appearance similar to the Indian specimens (Deb and Raychaudhuri, 1975). Three main differences are as follows:

1) Body longer (348-390 versus 319-325 in Indian specimens). We believe these differences represent intraspecific (perhaps geographical) variability.

2) Anterior notogastral margin is well visible (versus completely absent in Indian specimens); also, the text of other paper (Sarkar et al. 2007) on $G$. (G.) crenata assert that it is present.

3) Rostral, lamellar and interlamellar setae developed (versus absent in Indian specimens). We believe these differences can be erroneous. The reason is that Deb and Raychaudhuri (1975) inadequately described this species and, probably, they overlooked these setae, because the rostral setae are usually strongly pressed to the prodorsum surface and are often not visible in dorsal and ventral views, and the lamellar and interlamellar setae are minute, well visible only under high magnification.

\section{Key to species of Galumna (Galumna) of the Philippines}

1 Rostrum pointed; porose areas $A a$ boomerang-like; body size: 647-680 × 498-547 .................. G.(G.) makilingensis sp. n. Distribution: Philippines.

- $\quad$ Rostrum rounded; porose areas $A a$ not boomerang-like ............................. 2 
2 Lamellar and interlamellar setae well developed, long; bothridial setae lanceolate; body size: $425-482 \times 305-344$

G. (G.) khoii Mahunka, 1989. Distribution: Vietnam and Pilippines.

- $\quad$ Lamellar and interlamellar setae minute or absent; bothridial setae clavate....3

3 Porose areas $A a$ elongated, transversally oriented, boot-shaped or weakly triangular; anterior tectum of epimere I dentate; body size: 319-390 × 249-290 G. (G.) crenata Deb \& Raychaudhuri, 1975 (including our data). Distribution: India and Philippines.

- $\quad$ Porose areas $A a$ rounded; anterior tectum of epimere I smooth.................... 4

4 Bothridial heads densely ciliale; anterior notogastral margin developed; body size: $303-348 \times 204-220$. G. (G.) flabellifera Hammer, 1958 (see also Aoki 1964, 1965, 1982). Distribution: Pantropics and Subtropics. - $\quad$ Bothridial head smooth; anterior notogastral margin not developed; body size: $330 \times 264$

... G. (G.) cf. exigua Sellnick, 1925. Distribution: Sumatra and Philippines.

\section{Acknowledgements}

We cordially thank Prof. Dr. Badamdorj Bayartogtokh (National University of Mongolia, Ulaanbaatar, Mongolia) and one anonymous reviewer for the valuable comments, Mr. Orlando Eusebio and Jeremy Naredo (Museum of Natural History, University of the Philippines Los Baños, College, Laguna, Philippines) for facilitating dispatchment of the specimens, together with other oribatids, to Russia.

\section{References}

Aoki J (1964) Some oribatid mites (Acarina) from Laysan Island. Pacif. Ins. 6(4): 649-664.

Aoki J (1965) Oribatiden (Acarina) Thailands. I. Nat. Life South. Asia 4: 129-193.

Aoki J (1982) New species of oribatid mites from the southern island of Japan. Bul. Ins. Env.

Sci. Tech., Yokohama Nat. Univ. 8: 173-188.

Bayartogtokh B, Akrami MA (2014) The soil mite family Galumnidae of Iran (Acari: Oribatida).

J. Nat. Hist. 48(15-16): 881-917. doi: 10.1080/00222933.2013.840397

Corpuz-Raros LA (1979) Philippine Oribatei. I. Preliminary list of species and descriptions of forty new species. Philip. Agr. 62(1): 1-82.

Corpuz-Raros LA, Gruèzo WS (2011) New species and records of Oribatida and other soilinhabiting mites (Acari) mainly from Luzon and Mindanao Islands, Philippines. Asia Life Sci. 20(1): 37-61.

Deb DC, Raychaudhuri DN (1975) Three galumnids (Acari, Cryptostigmata) from West Bengal, India. Ann. Zool. Jpn. 48(3): 167-171.

Engelbrecht CM (1969) Some South African species of the genus Galumna von Heyden, 1826 (Acari: Galumnidae). Journ. Ent. Soc. South. Africa 32(1): 99-122. 
Ermilov SG, Anichkin AE (2011) The galumnoid fauna (Acari: Oribatida) of Cat Tien National Park (southern Vietnam) with descriptions of two new species. Int. J. Acarol. 37 (Suppl. 1): 85-94. doi: 10.1080/01647954.2010.539982

Ermilov SG, Sidorchuk EA, Rybalov LB (2011) Three new species of oribatid mites (Acari: Oribatida: Galumnoidea) from Ethiopia. Int. J. Acarol. 37 (Suppl. 1): 2-17. doi: 10.1080/01647954.2010.528799

Ermilov SG, Starý J, Sandmann D, Marian F, Maraun M (2013) New taxa and new records of oribatid mites of the family Galumnidae (Acari: Oribatida) from Ecuador. Zootaxa 3700 (2): 259-270. doi: 10.11646/zootaxa.3700.2.4

Hammer M (1958) Investigations on the oribatid fauna of the Andes Mountains. I. The Argentine and Bolivia. Det Kong. Dansk. Vidensk. Selsk. Biol. Skr. 10: 1-129.

Heyden C (1826) Versuch einer sistematischen Einteilung der Acariden. Isis, Oken 1(4): 607-613.

Mahunka S (1989) A survey of the Oribatid fauna (Acari) of Vietnam, III. Folia Ent. Hung. 50: 47-59.

Norton RA, Behan-Pelletier VM (2009) Oribatida. Chapter 15. In: Krantz GW, Walter DE (Eds) A Manual of Acarology. Texas Tech Univ. Press, Lubbock, 430-564.

Sarkar S, Sanyal AK, Chakrabarti S (2007) A new species of the genus Galumna Heyden, 1826 (Acarina: Oribatida: Galumnidae) from Uttarakhand, India. Rec. Zool. Surv. India 107 (4): 13-16.

Sellnick S (1925) Fauna sumatrensis (Oribatidae). Suppl. Ent. 10: 79-89.

Subías LS (2004) Listado sistemático, sinonímico y biogeográfico de los ácaros oribátidos (Acariformes: Oribatida) del mundo (excepto fósiles). Graellsia 60 (número extraordinario): 3-305. [accessed in February 2014, 577 pp.] 